\title{
Kenya's fertility transition: Trends, determinants and implications for policy and programmes
}

\author{
Ian Askew \\ Population Council \\ Alex C. Ezeh \\ John Bongaarts \\ Population Council \\ John Townsend \\ Population Council
}

Follow this and additional works at: https://knowledgecommons.popcouncil.org/departments_sbsr-rh

Part of the Demography, Population, and Ecology Commons, Family, Life Course, and Society Commons, Gender and Sexuality Commons, Health Policy Commons, International Public Health Commons, Medicine and Health Commons, and the Women's Health Commons How does access to this work benefit you? Let us know!

\section{Recommended Citation}

Askew, lan, Alex C. Ezeh, John Bongaarts, and John Townsend. 2009. "Kenya's fertility transition: Trends, determinants and implications for policy and programmes." Nairobi: Population Council. 


\section{Kenya's Fertility Transition:}

Trends, Determinants and Implications for Policy and Programmes

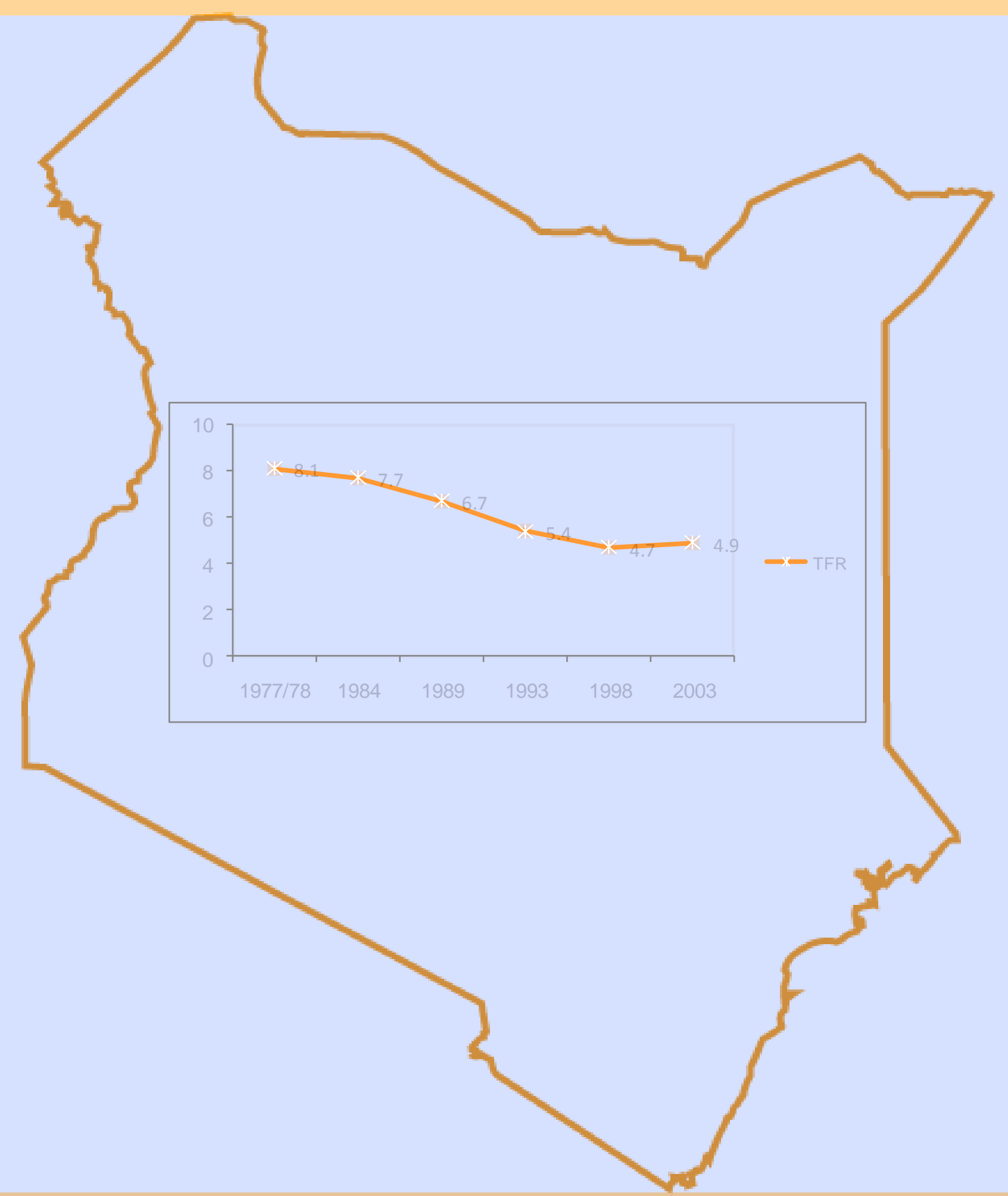




\section{(2) Population Council}

The Population Council conducts research worldwide to improve policies, programs, and products in three areas: HIV and AIDS; poverty, gender, and youth; and reproductive health.

(C) 2009The Population Council, Inc.

Any part of this publication may be reproduced without permission for limited distribution provided it is distributed without charge and the Population Council is acknowledged as its source. The Population Council would appreciate receiving a copy of any materials in which the text is used.

Suggested citation: Suggested citation: Ian Askew, Alex Ezeh, John Bongaarts and John Townsend. 2009. Kenya's Fertility Transition: Trends, Determinants and Implications for Policy and Programmes. Population Council. Nairobi 


\title{
Kenya's Fertility Transition:
}

\section{Trends, Determinants and Implications for Policy and Programmes}

\author{
Ian Askew \\ Director, Reproductive Health Services and Research \\ Population Council \\ Nairobi, Kenya \\ Alex Ezeh \\ Executive Director, \\ Africa Population and Health Research Centre \\ Nairobi, Kenya \\ John Bongaarts \\ Vice President and Distinguished Scholar \\ Population Council \\ New York, USA \\ John Townsend \\ Director, Reproductive Health Program \\ Population Council, Washington DC, USA
}

\section{(f) Population Council}




\section{Contents}

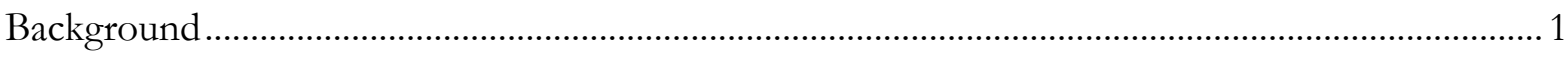

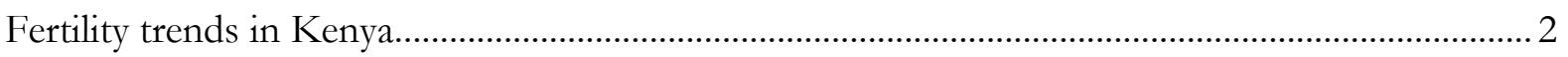

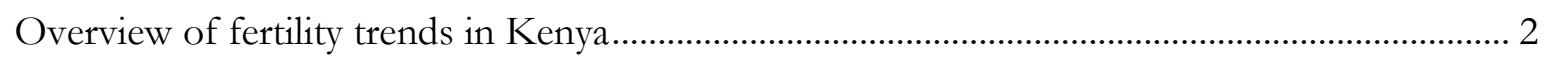

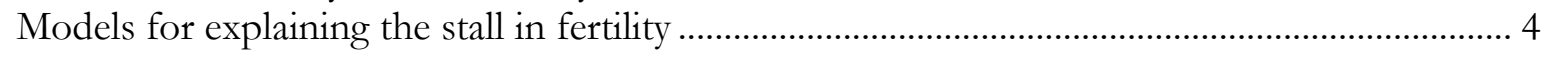

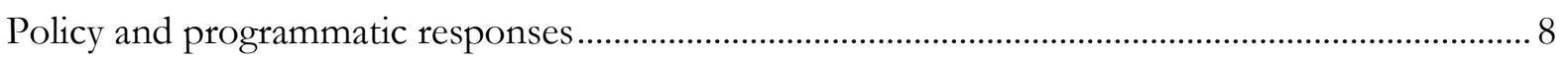

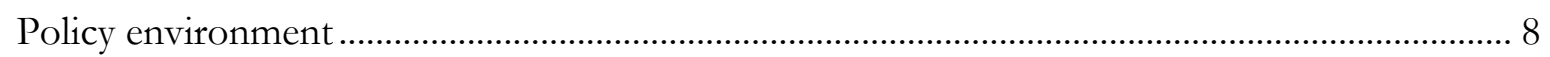

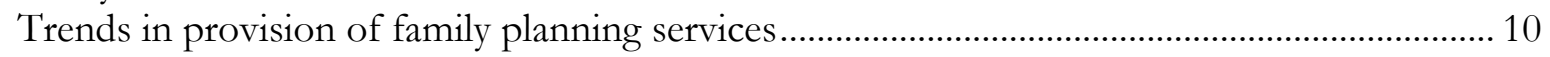

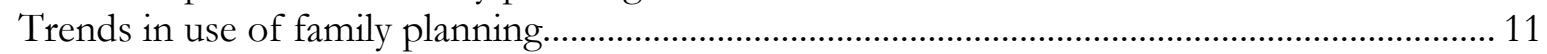

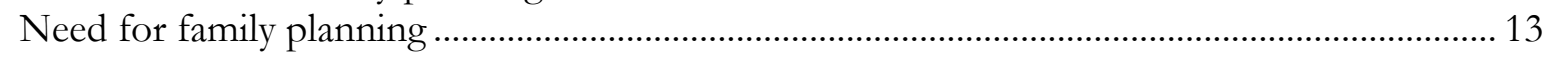

What happened and why: Implications for population dynamics and development planning

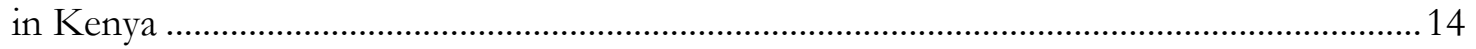

Summary of relevant developments in population issues in Kenya .............................................. 14

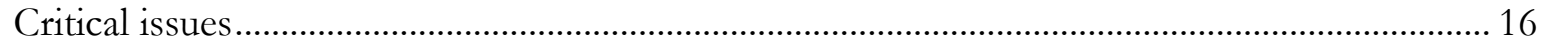

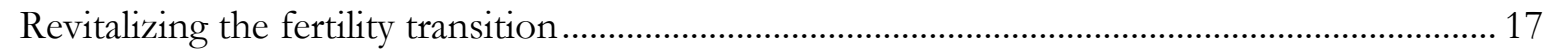

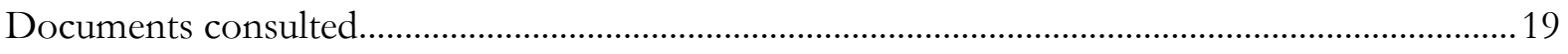

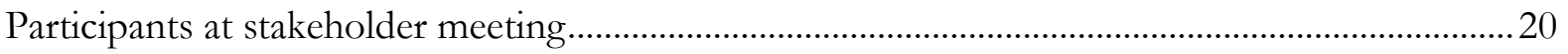




\section{Background}

Population projections usually assume that once a fertility decline has been initiated in a population it will continue until fertility drops to, or below, replacement level. Estimates from recent surveys in a number of African countries, however, indicate that fertility rates in the 1990s declined less rapidly than had been projected, and in a few cases the fertility transition appears to have stalled. This surprising development has serious implications for future population growth because projected population size is sensitive to minor variations in current fertility trends.

Figure 1 presents trends in fertility rates for all 16 countries with three DHS surveys in subSaharan Africa (SSA) ${ }^{1}$. The three points plotted for each country give the total fertility rates (TFR) measured in, respectively, the second to last survey (around 1993), the next to last survey (around 1998) and the most recent survey (around 2004). The solid line represents Kenya. Kenya's fertility is, on average, somewhat lower than in most other countries in the region - but it is also one of the few countries in which the fertility rate rose between the last two surveys. Nevertheless often the changes in fertility between surveys are so small as to be statistically insignificant.

\section{Figure 1: Trends in fertility of 16 sub-Saharan countries with three DHS surveys}

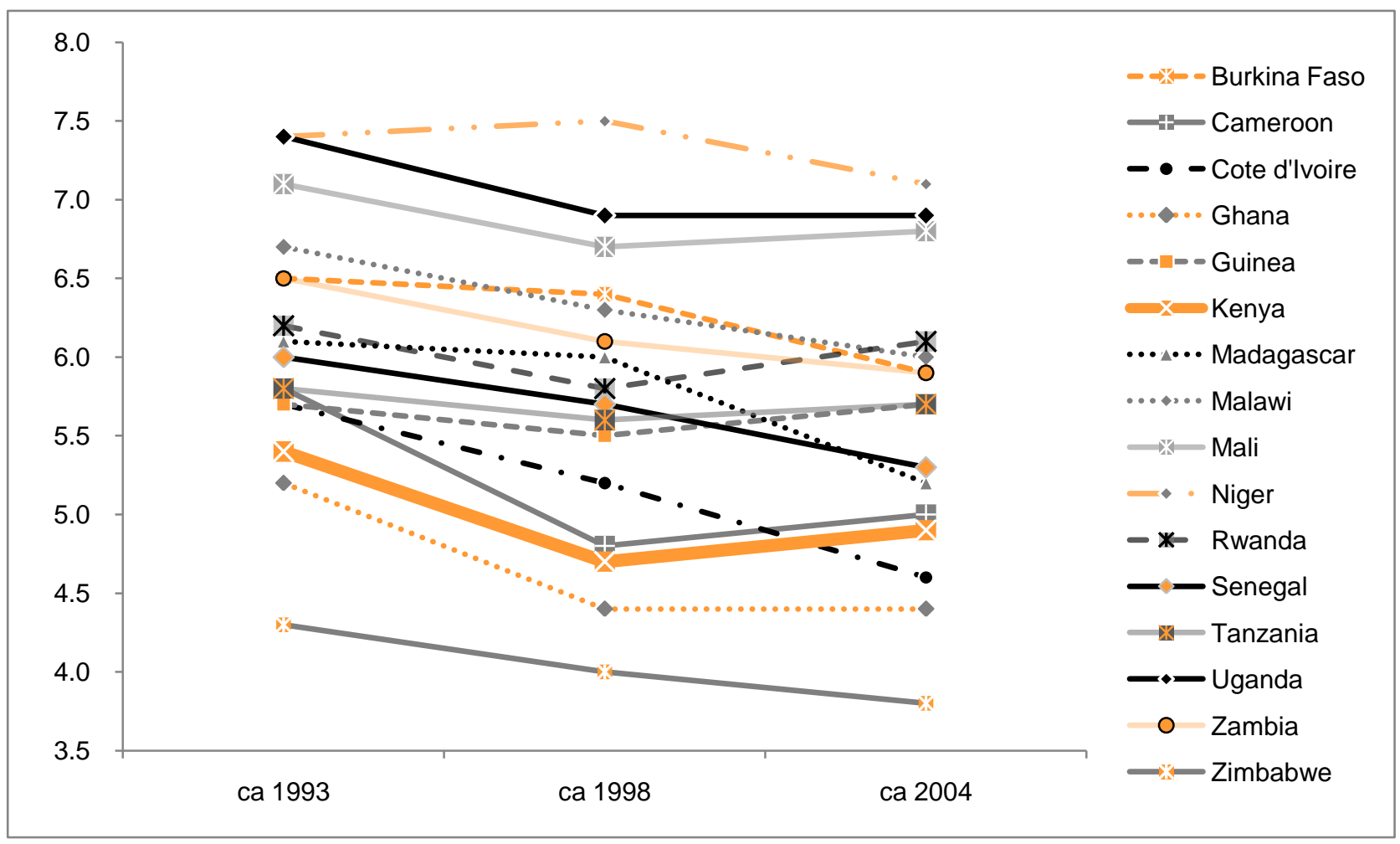

Source: Bongaarts 2008

These 16 countries can therefore be divided into the following subgroups:

- Stalled transitions: Cameroon, Ghana, Guinea, Kenya, Mali, Rwanda, Tanzania, Uganda;

- Insignificant declines: Zambia, Zimbabwe;

- Significant declines: Burkina Faso, Cote d'Ivoire, Madagascar, Malawi, Niger, and Senegal.

${ }^{1}$ Data from DHS first country reports available online at http:/ /www.measuredhs.com/ 
These results indicate that stalling is not unusual among these 16 countries: half of them have experienced a stall, including fertility reversals, and an additional two countries experienced insignificant declines. It is noteworthy that fertility stalls were much less common during the next to last survey interval in the mid-1990s and that the pace of decline was substantially faster in the mid-1990s than in the last survey interval between the late 1990s and early 2000s. The average pace of decline in fertility in the region dropped from 0.4 per year in the mid 1990 s to 0.1 per year around 2000 .

Recognizing the challenges that this stall poses to the economic, health and social development of Kenya, the David and Lucile Packard Foundation supported the Population Council to undertake the following:

- Review the existing evidence and offer analytical perspectives on the magnitude and distribution of the fertility transition in Kenya.

- Identify and review key policy and programmatic actions appropriate for supporting fertility decline and their perceived effectiveness within various socio-demographic settings.

- Recommend policy and programmatic investments that would support and stimulate appropriate change in these provincial and national scenarios.

To achieve these objectives, the Council and collaborators prepared a series of demographic and policy analyses that drew from the existing literature on fertility and family planning in Kenya. These analyses were presented at a meeting of key stakeholders in Kenya on November $20^{\text {th }}$, 2008, during which the issues raised were discussed and debated extensively.

This report presents the issues emerging from the analyses and discussions and suggests some policy and programmatic actions that the Packard Foundation or others may support that would help the Government of Kenya to address the stall within the frameworks of the Millennium Development Goals and its 'Vision 2030' plan for the sustainable development of the country. The results of the forthcoming DHS are eagerly awaited as these may require a re-analysis of some of these issues.

\section{Fertility trends in Kenya}

The literature on fertility transitions in sub-Saharan Africa suggests that the early transition was observed across nearly all age groups, socio-economic groups and countries in this region. This was seen as a departure from the experiences of other regions where specific groups (generally urban and educated women) led in the transition, before the behaviour and social norms associated with it diffused to other groups. In looking at the current stall in the fertility transition in Kenya, therefore, it is important to determine whether all sub-groups of the Kenyan population have been equally affected by the stall in fertility, and if not, whether there are specific sub-group characteristics that could explain why the stall has happened.

\section{Overview of fertility trends in Kenya}

In 1968, Kenya was one of the first countries of sub-Saharan Africa to develop a national population policy. This policy, however, remained largely dormant until the findings from the World Fertility Survey (WFS) in 1977 showed that Kenya had one of the highest fertility rates in the world, with a total fertility rate (TFR) of 8 children per woman. This statistic served to focus both policy and public attention on fertility issues and to reinvigorate the population policy, with the result that substantial national and international support was dedicated to developing and strengthening a vigorous national family planning programme. The impact of this investment of 
human and financial resources was remarkable, as the contraceptive prevalence rate increased rapidly (Figure 2) and fertility declined (Figure 3) in the following decade. Indeed, the decline in fertility between 1977 and 1998, from 8.1 to 4.7 births per woman, was one of the most rapid ever documented. This consistent decline in fertility led to projections that the TFR would decline gradually to about 3.5 by 2008 .

Figure 2: Trends in contraceptive use among currently married women

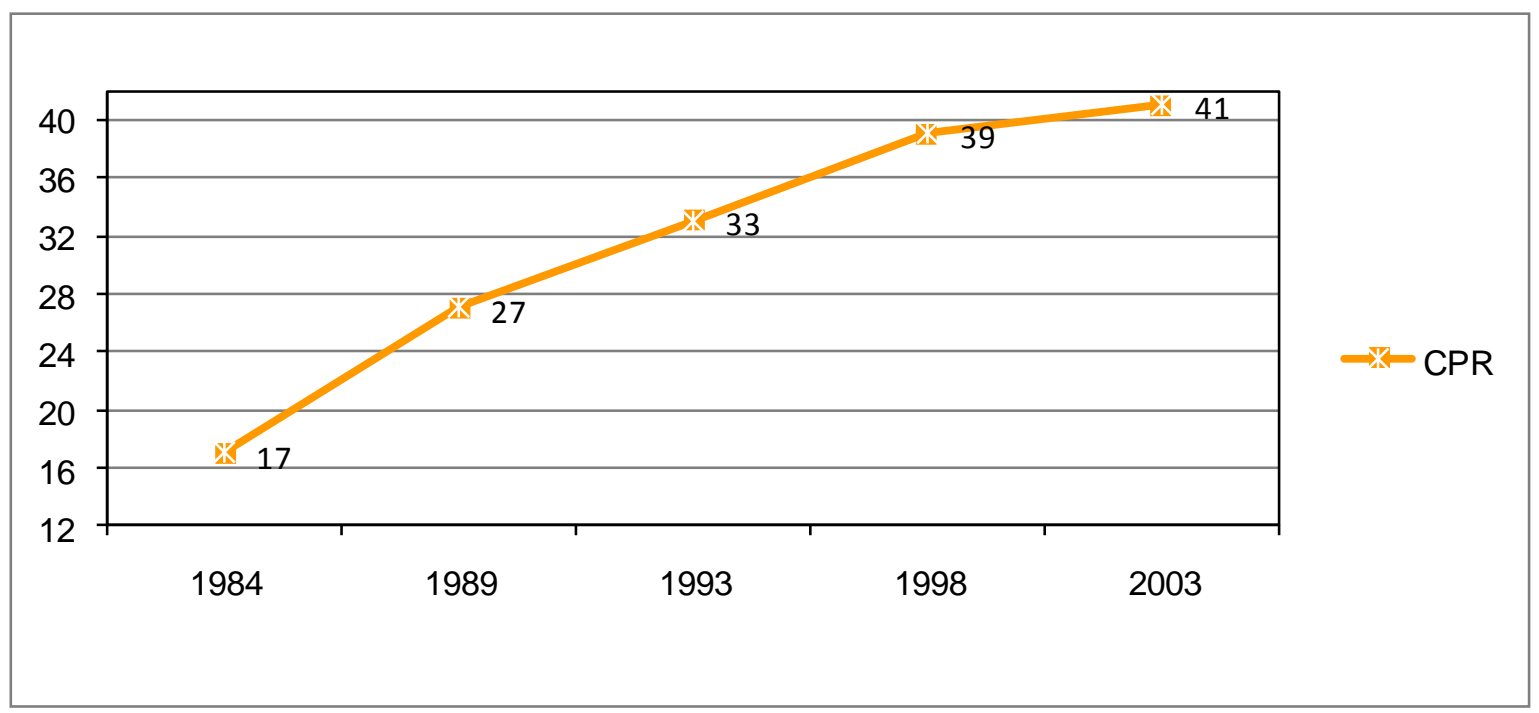

Figure 3: Fertility trends in Kenya

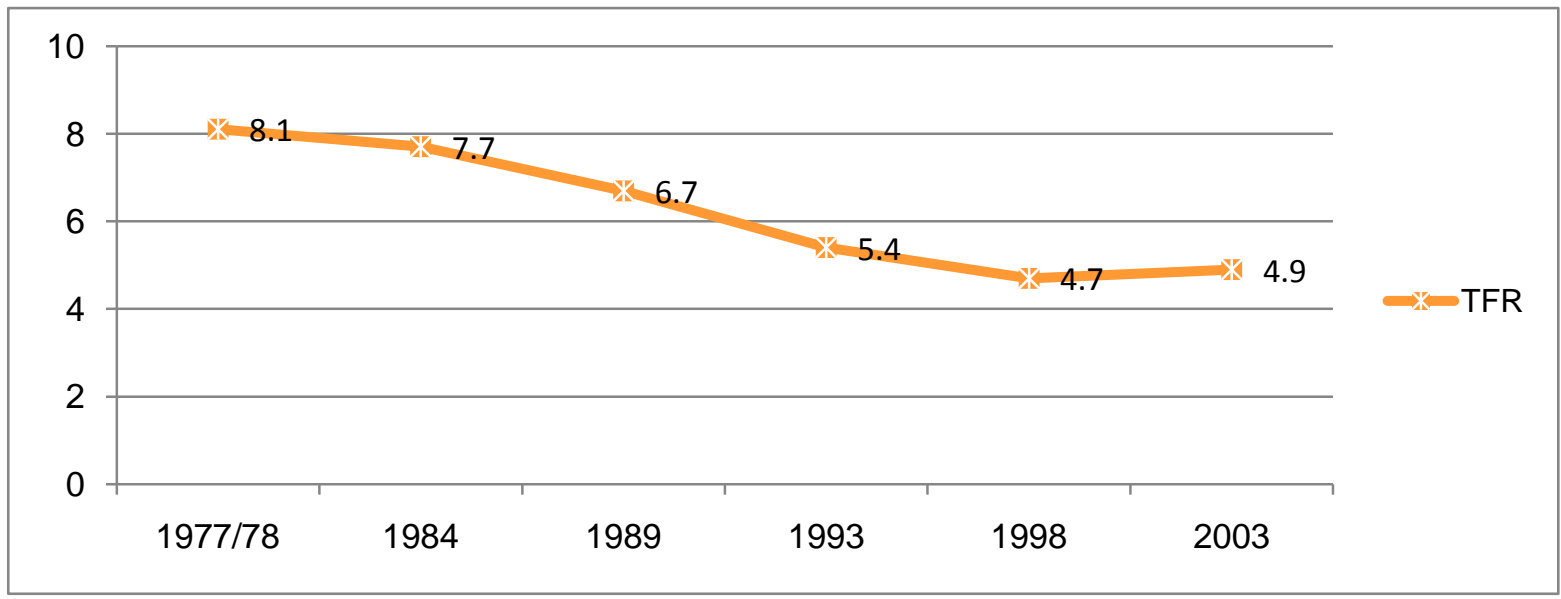

Source: Westoff and Blanc 2006

Between 1977 and 1993 the rate of decline in fertility increased, but by 1998 the rate of decline had begun to slow, and by 2003 the decline in fertility had stalled. These trends indicate that the stall in decline could have started earlier than initially thought for some population sub-groups. Indeed, for younger women, especially those aged 15-19, their fertility levels had remained constant between 1993 and 2003, suggesting that the stall in their fertility decline probably started earlier than 1998. This may have been due to the slower changes in the patterns of early marriage, than the sexual behaviour and contraceptive practices of women within marriage. 
The implications of the fertility stall have been discussed broadly in various forums and publications. By 2003, the clear evidence of a stall led the United Nations Population Division to revise its projected population size by 2050 for Kenya from 44 to 83 million, a remarkable difference with significant implications for development. The original projections had assumed a continued decline in fertility, reaching about 3 births per woman by 2015 and 2 births per woman by 2050 . What factors drove this stall in Kenya's fertility decline?

\section{Models for explaining the stall in fertility}

Three models can be proposed for explaining the observed fertility stall in Kenya. The first is the reproductive behaviour model, which focuses on changes in fertility preferences or behaviour. This model suggests that countries with a stall in fertility are likely to have experienced a stall or reduced pace of change in the use of effective contraception and/or in desired family size. There may also be shifts in marriage patterns and the timing of initiating childbearing, and these changes may vary across different sub-groups.

The second model examines changes in institutional factors, defined primarily by shifts in local or national policy or service delivery environments. Specifically, decreases in the level of support for the family planning programme, at the local and national levels and/or through reduced international donor support, may drive a stall in fertility decline through increasing unmet need for family planning, increasing levels of unwanted childbearing, declining knowledge of family planning methods or sources, or increasing negative attitudes toward family planning, including myths and concerns about side effects.

The third model focuses on changes in socio-economic and demographic characteristics. Fertility has been known to vary significantly by a number of socio-economic and demographic characteristics of a sub-population (for example, the age structure of the population), shifts in which could lead to temporal changes in fertility levels and overall trends in fertility. In addition, shifts in programme efforts may affect different sub-groups differentially; for example charging service fees for contraceptive services in an effort to enhance their sustainability often creates barriers for youth or the lowest economic quintile of women seeking services. Each of these factors could contribute independently or jointly to observed changes in fertility levels, in subgroups or a total population.

Analyses of data from several Demographic and Health Surveys (DHS) for Kenya show some support for all of these models as having a role to play in explaining the fertility stall; in particular, the following shifts correlate statistically with the stall in the fertility transition in Kenya.

\section{A stalled decline in unwanted fertility}

Unwanted fertility almost halved in the period 1993-1998, from 2.0 to 1.2, probably as a result of a highly effective family planning programme. However, this decrease not only stalled from 1998 to 2003 , but unwanted fertility actually increased overall to 1.3 during this period. The subpopulation that contributed most to this increase was the poorest wealth quintile, in which unwanted fertility increased from 1.8 to 2.6. This suggests that, from the late-1990s, the family planning programme was not effectively reaching the poorest of the poor with contraceptive services. This may have been the result of service delivery outlets serving the growing number of users in higher wealth quintiles and the increasing role of the private sector in providing family services, with a corresponding increase in the charging of fees for services. 


\section{A stalled decline in wanted fertility}

Probably the most important element of the stalled fertility transition is that wanted fertility did not decline over the period 1993-2003; indeed, among all women it increased slightly from 3.4 to 3.5 births per woman. The increase in desired family size was most marked in the lowest wealth quintile (from 4.7 to 5.2) and among those with less education (from 4.2 to 5.5). This evidence of a stall and then slight increase in the ideal family size can also be seen in terms of the slight decrease in the proportion of currently married women who want no more children (Figure 4).

Figure 4: Trends in desired family size and unwanted fertility

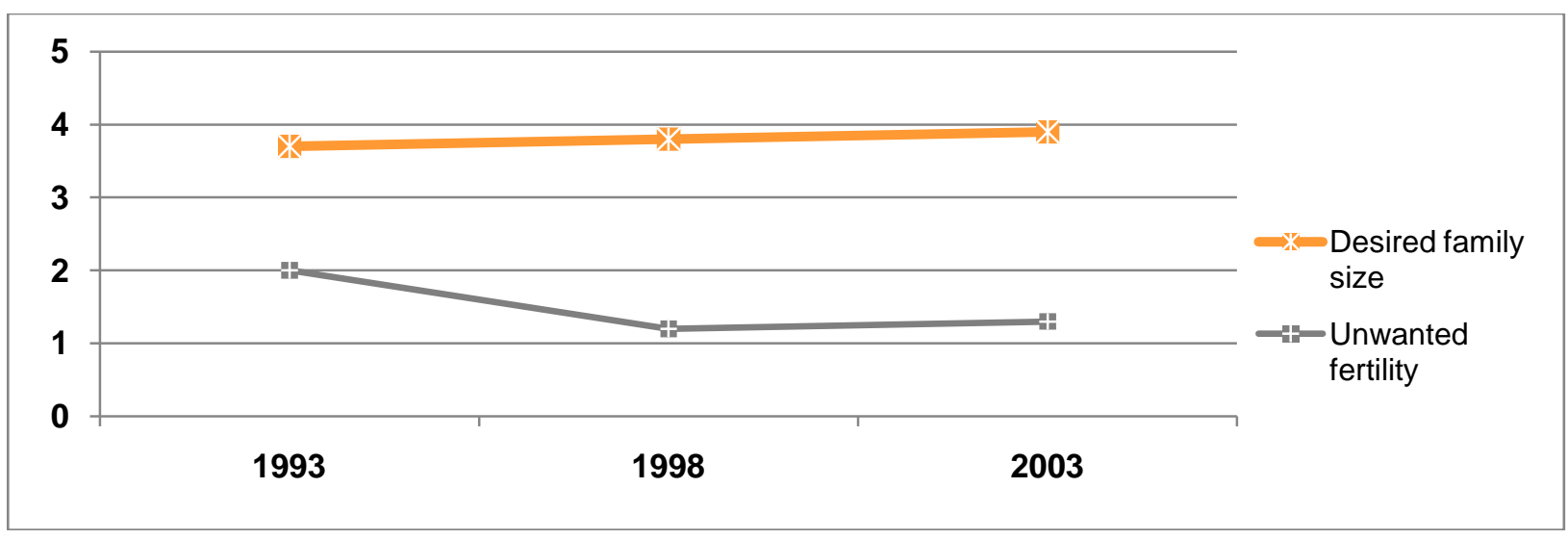

In addition to the marked increase among the poorest and those with the least education, women reporting their religious affiliation as Islam also showed a 14 percentage point decrease in those wanting no more children, from 43 percent in 1993 to 29 percent 2003. A stagnation or slight increase in wanted fertility was found consistently across residence, province and ethnicity. Religious opposition to family planning was never a major barrier to use in Kenya; however the confounding of family planning with abortion in the early 2000s certainly led to more conservative expression of public views in the media.

\section{Age}

Trends in age-specific fertility rates show that the stall in fertility decline occurred evenly across all age groups. It is important to note that one sub-population, urban teenagers, appears to have also had a substantial increase in pregnancy rates between the DHS surveys of 1998 and 2003, from 18 to 22 percent, with an even greater increase among those living in Nairobi province (from 10 to 20 percent). Teenagers with no education have the most dramatic increase, from 30 to 55 percent over the period 1993 to 2003 . The other surprising trend is that among those with at least secondary education, teenage pregnancy increased from about 10 percent to up to 21 percent during the period.

\section{Wealth}

Kenyan women living in the poorest 20 percent of households currently have more than two and half times the total fertility rate (TFR) of women in the richest 20 percent (see Figure 5). Furthermore, women in the lowest two wealth quintiles had between 1.5 to 2.2 more children than their desired family size. Conversely, women in the richest households were able to fully achieve their fertility preferences; it should be noted, however, that even women in the fourth quintile were having, on average, 0.5 births more than their desired family size. 
Figure 5: Fertility and ideal family size by wealth status

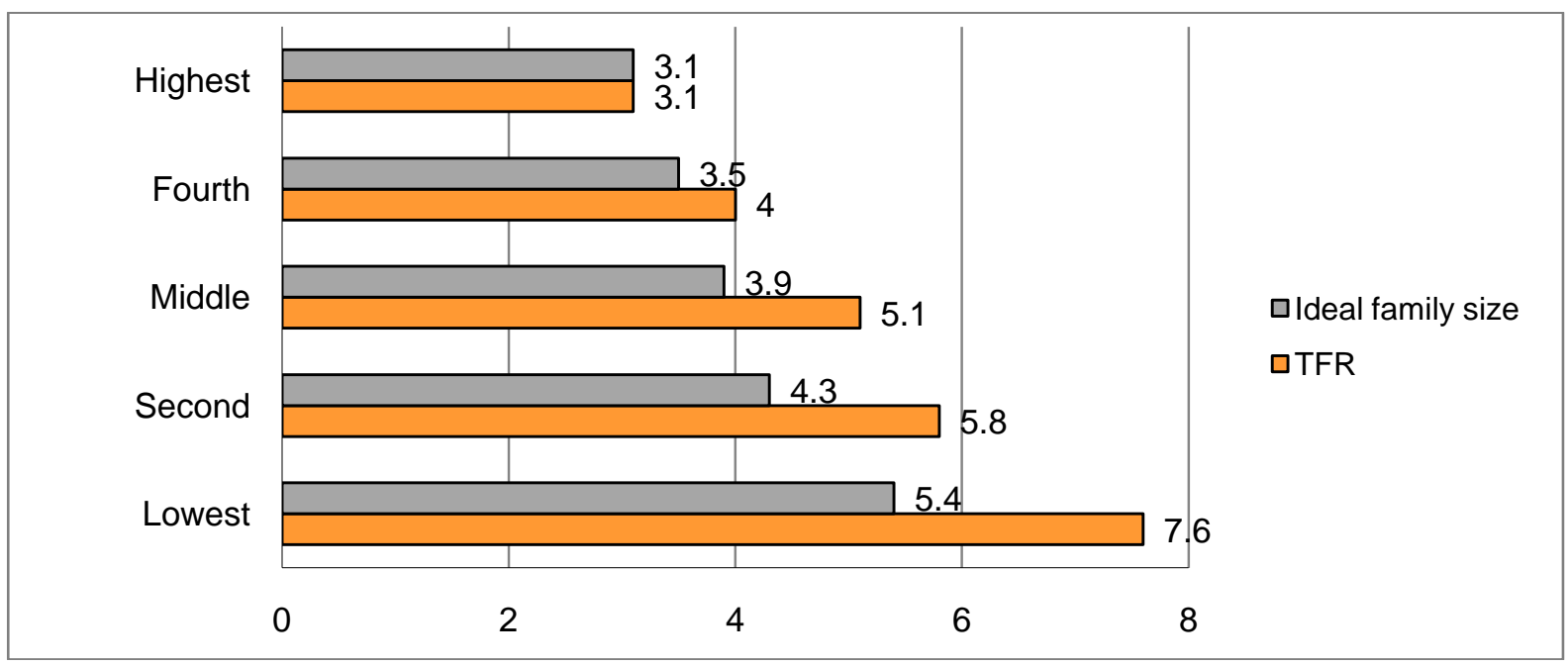

Moreover, while those in the richest households continued to experience a decline in the mean number of children over this period, the fertility of the poorest women has reversed, increasing by an average of more than 0.6 births per woman between 1998 and 2003, mainly due to high levels of unwanted fertility (Figure 6).

Figure 6: Trends in the number of children per woman for the lowest and highest wealth quintiles

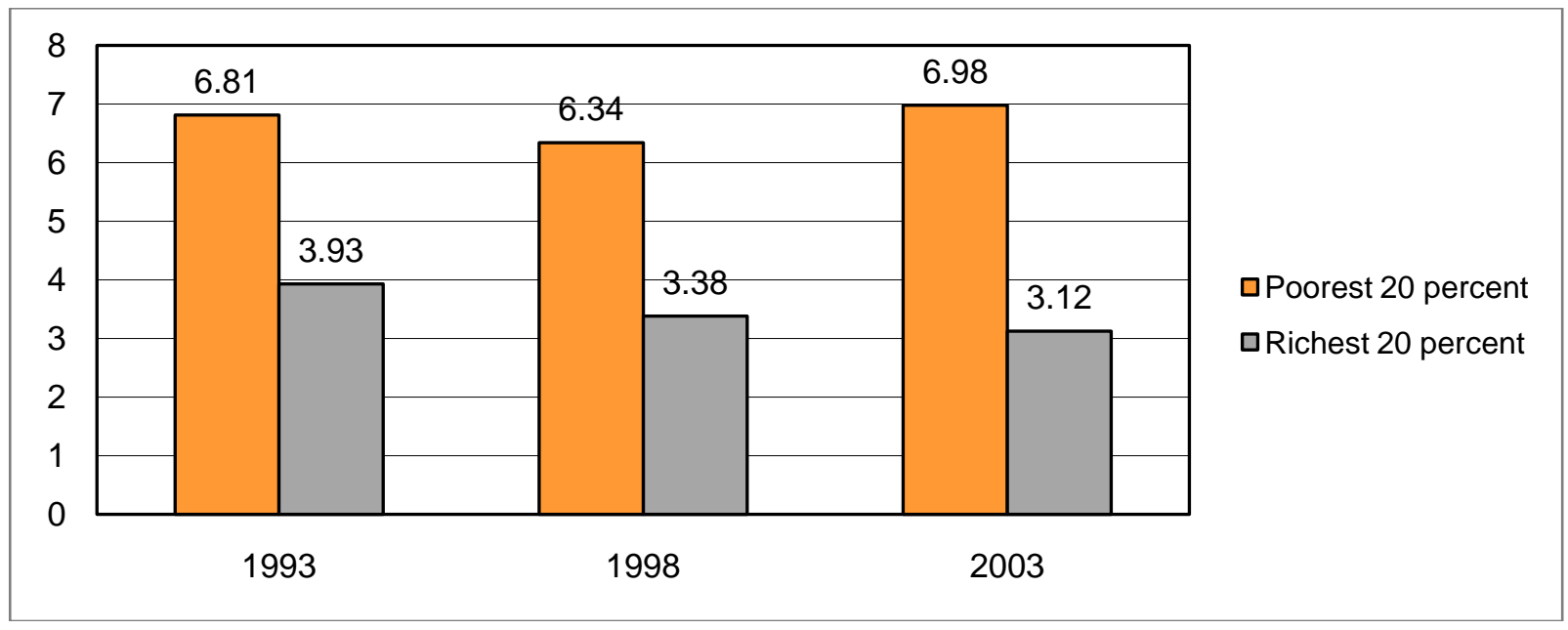

\section{Education}

Women with secondary or higher education continued to experience declines in their fertility, while the decline in the fertility of women with no formal education and those with only primary education reversed (Figure 7). Between 1998 and 2003, the fertility of women with no formal education increased by about one child on average. Indeed, the overall stall in fertility would have been larger if not for the sustained decrease among women with secondary or higher education. 
Figure 7: Trends in fertility by level of education

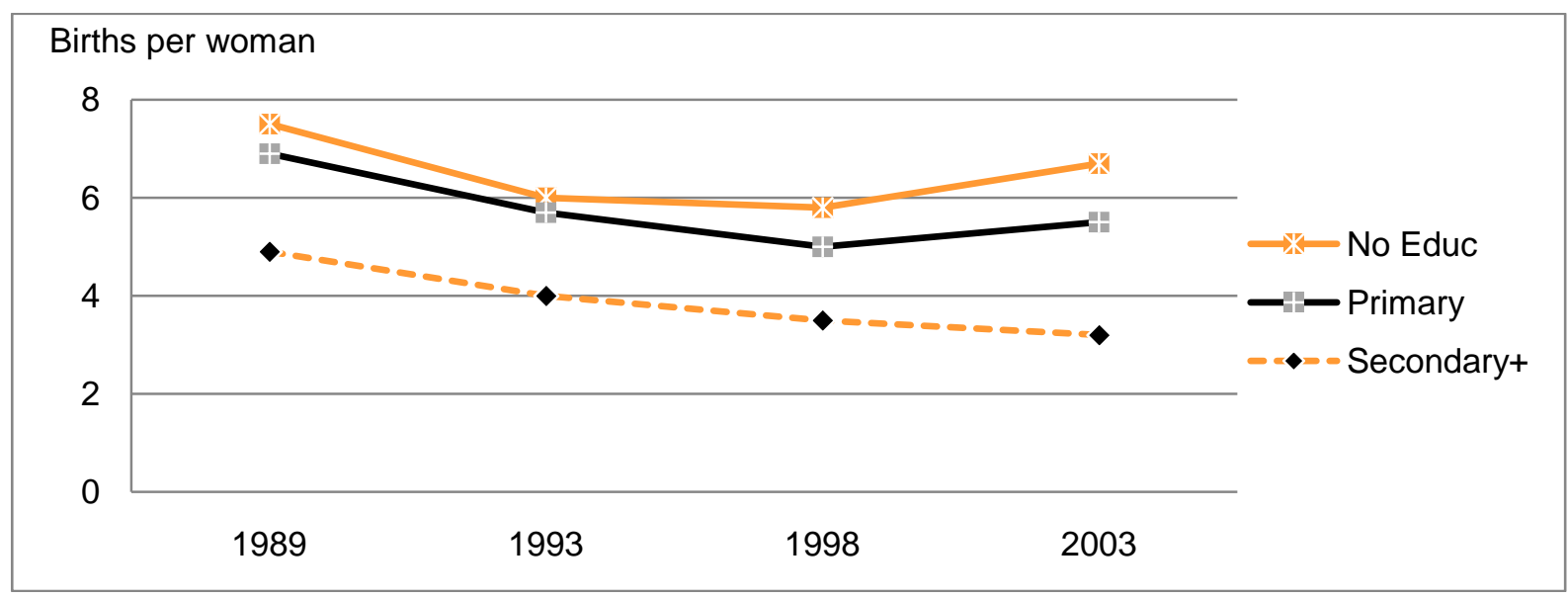

\section{Place of residence}

While most provinces experienced a stall in their fertility rates over the decade preceding 2003, the transition has continued in Central province, reaching 3.4 to make it the second lowest rate after the largely urbanized Nairobi province. Fertility rates decreased rapidly in the first five years and then increased equally rapidly in Nyanza (by 0.6 births) and Rift Valley (by 0.5 births) provinces, negating the gains made there and bring their fertility rates back up to 5.6 and 5.8 respectively. The stall was similar in both urban and rural areas, although over the ten year period rural areas had a larger decline (5.8 to 5.4 ) than urban areas (3.4 to 3.3).

\section{Child mortality}

The proportion of married women wanting another child is higher (55\%) among those experiencing a child's death in the previous five years than among those not experiencing a recent child death $(49 \%)$, indicating that an increase in child mortality can be expected to modestly increase fertility ${ }^{2}$. Kenya experienced a 15 percent increase in child mortality in the decade before the mid-1990s, suggesting that this may also be a contributing factor to the stalled transition. While deaths due to paediatric AIDS may explain some of this increase (in the 2003 DHS, 7 percent of HIV negative women reported the death of a child under five compared with 14 percent of HIV positive women), an acknowledged deterioration of infant and child health services is also a likely contributing factor.

\footnotetext{
${ }^{2}$ Westoff C. and A. Cross, 2006. The Stall in the Fertility Transition in Kenya, DHS Analytical Studies No. 9, Calverton, Maryland: ORC Macro.
} 


\section{Policy and programmatic responses}

\section{Policy environment}

As highlighted in Box 1, Kenya has had a host of policy statements and action strategies over the past four decades that have contributed to a supportive environment for addressing population issues generally, and fertility specifically. As one of the first countries in Africa to develop a population policy and establish a family planning programme as the main policy lever to reduce the population growth rate, Kenya was well-placed to initiate a fertility transition through government-led actions.

\section{Box 1: A brief history of relevant policies}

-1965: Population issues first highlighted in Sessional Paper No. 10 on African Socialism and Its Application to Planning in Kenya

-1967: Government adopted official population policy and established a national family planning action programme under the Ministry of Health, with an emphasis on reduction of family size and spacing of children to reduce population growth rate

-1982: Government established National Council for Population and Development (NCPD) in the Office of the Vice President and Ministry of Home Affairs. Role and mandate contained in 1984 Sessional Paper No. 4 on Population Policy Guidelines

-1994: 'Manage population growth' a strategic imperative Kenya Health Policy Framework and reiterated in NHSSP I and II

-1996: NCPD publishes National Population Advocacy and IEC Strategy for Sustainable Development (until 2010)

-1997: National Reproductive Health Strategy (19972010) launched

-2000: Sessional Paper No. 1 on second National Population Policy for Sustainable Development (NPPSD)

-2003: Adolescent Reproductive Health and Development policy

-2004: National Coordinating Agency for Population and Development replaces NCPD

-2005/6: Parliamentary budget allocates Government funds to family planning for the first time

-2007: National Reproductive Health Policy published

-2007: Population growth, and especially urban and vouna. mentioned in Vision 2030 document
As documented above, Kenya achieved a rapid fertility decline, in large part because of the strong official commitment of the government and substantial funding and technical support from a range of bilateral and multilateral development partners. Indeed, when the results from the 1993 DHS survey were released, Kenya's success in achieving a phenomenal decline in fertility was lauded globally and many national and international observers felt that social norms in favour of small families and increased use of contraception were now well established and irreversible. Kenya had established a strong and diverse family planning programme, immersed in both public and private sectors, which benefited from high levels of support from external sources.

Over the decade following the mid1990s, two components of the national family planning programme were substantially reduced, following the withdrawal of funding from donors and only modest investments from the government: i) the large-scale community-based distribution (CBD) programmes which allowed low-cost contraceptive information and services to reach rural and peri-urban communities; and ii) the nationwide

IEC campaigns advocating in favour of small families and the use of contraception, which contributed to changing the acceptability of new social norms around fertility. Both of these components had been introduced as demand creation strategies; the drastically reduced investment in these strategies at this time probably reflects the perception that the demand for family planning was sufficiently well-established in the general population and that the programme's focus should consequently shift to addressing the resulting unmet need. 
The effect of decreasing investment in and attention to demand creation strategies for family planning is starkly illustrated in Table 1 . The proportions of women knowing a family planning method and its source decreased for women across all levels of education including an 11 percentage point decline for those with secondary education, but especially for those with no education. Similarly, approval of family planning, either as a family health or national development strategy, also decreased across all women, and especially among those with no education.

Table 1: Declining awareness about family planning

\begin{tabular}{lccc|ccc}
\hline & \multicolumn{2}{c|}{ Know method and source } & \multicolumn{4}{c}{ Approve of FP } \\
\hline & 1993 & 1998 & 2003 & 1993 & 1998 & 2003 \\
No education & 80 & 64 & 48 & 81 & 74 & 54 \\
Primary & 93 & 84 & 80 & 92 & 89 & 86 \\
Secondary + & 98 & 94 & 87 & 97 & 94 & 94 \\
\hline
\end{tabular}

Source: Koome et al, 2005

Several other factors also influenced funding, policy and programmatic decisions concerning the family planning effort in the 1990s. The International Conference on Population and Development (ICPD) in 1994 affirmed the importance of providing family planning within a rights-based framework and as part of a comprehensive set of services to meet individual reproductive health needs and address broader development concerns. While this undoubtedly broadened the range and quality of reproductive health services provided in Kenya, the energies and resources expended on re-aligning policies, programmes and services almost certainly diluted the attention being paid to basic family planning services. Long-standing donor investment in family planning in Kenya had been seen to produce a major fertility decline and many donors either re-directed their investments into a broader range of $\mathrm{MCH}$-related services, emerging priorities such as HIV, or in basket funding to the government to support a range of social investments.

Within Kenya, the 1990s were also characterised by declining growth in the GDP and increases in the proportion of the population (now nearly half) living below the poverty line. At the same time, political tensions increased significantly following the introduction of a multiparty system at the 1992 elections. Both factors absorbed the attention of politicians, other influential leaders and indeed the general population, and so the family planning "success story" soon become yesterday's news and attention to population issues generally, and fertility decline specifically, gradually waned. This political turbulence also facilitated a rise in public advocacy against family planning from conservative religious leaders and "pro-life" groups, leading many senior politicians to be more cautious in making any public statements around reproductive health generally, and family planning in particular.

There is evidence of a decline in international and national support for the family planning programme since the mid to late 1990s, which mirrors the decrease in overall official development assistance to Kenya over the same period (from a high of above $\$ 1$ billion in the late 1980 s to under $\$ 400$ million by 2000 ). The timing of this decrease also parallels the stall in fertility decline, although the magnitude of the effect of this decrease in development assistance 
has not been fully evaluated. An increase followed by a decrease in institutional commitment to family planning programmes appears also to have affected the stall, with the timing of these changes in commitment and corresponding program effort closely mirroring the decline and then stagnation in the fertility rate ${ }^{3}$.

Realization that HIV and AIDS were reaching pandemic proportions, as demonstrated by President Moi's declaration of a national disaster in 1999, diverted national and international attention and resources into fighting the epidemic. Not only did this reduce the funding allocated for family planning services, it also reduced the levels of national and international technical expertise available and, importantly, took well-trained health personnel and support systems away from reproductive health to work in the newly created HIV/AIDS programmes.

The 1998 DHS showed a four percentage point increase in contraceptive prevalence from 1993 (from $26 \%$ to $30 \%$ ) and total fertility again declined substantially over the same period, from 5.4 to 4.7. These findings reinforced the impression that the fertility transition in Kenya was well and truly established and that the strategies being implemented and levels of funding available for both creating and supplying demand were appropriate for a country at this stage of the fertility transition. Consequently, the results of the 2003 DHS came as a shock to most observers, national and international, and a flurry of activities ensued to try to "reposition" both family planning and population as key issues worthy of attention and investment. For example, the Government replaced the NCPD with a National Coordinating Agency for Population and Development (NCAPD) and the Millennium Development Goals provided a platform for the role of population growth in sustainable development to be revisited and addressed.

In recent years, many development partners have sought ways to increase their investments in support of family planning services, but their gradual disengagement over the previous decade has meant that it has been difficult to make convincing arguments to increase allocations for family planning in the face of other development challenges, e.g., transportation, infrastructure and education. This document, and the stakeholders' meeting on which it is based, is just one of a number of initiatives that seek to inform international and national opinion on the value of addressing the unanticipated fertility stall in Kenya.

\section{Trends in provision of family planning services}

Family planning services were first made available in Kenya in the 1950s by private doctors, albeit modestly, and from 1962 by the Family Planning Association of Kenya (FPAK) (now called Family Health Options of Kenya (FHOK)). The Ministry of Health started providing a range of family planning services in 1967 through the network of MCH / Family Welfare Centres. Community-based distribution programmes were introduced in 1982, but by the late 1990s most had ended. Marie Stopes International (MSI) started offering services in 1985 through static clinics and diverse outreach strategies. Long-acting and permanent methods (LAPMs) were strengthened in the late-1980s - mid-1990s, including sterilization, vasectomy, IUDs and the introduction of implants and the major sources for these methods are MSI and FHOK. Social marketing of condoms and pills begin in the 1990s, primarily by Population Services International (PSI) and GTZ.

An important trend to note over the past 15 years has been the increased diversity of sources of family planning services and the decreasing role of the public sector. In 1993, 68 percent of women reported getting their method from a public source, and this decreased to 58 percent in

\footnotetext{
${ }^{3}$ Crichton, J. 2008. "Changing fortunes: analysis of fluctuating policy space for family planning in Kenya", Health Policy and Planning, 23(5): 339-350.
} 
1998 and to 53 percent in 2003. This decrease is particularly evident for the pill (from 73 to 49\%), with a shift to pharmacies, and for the IUD (from 69 to 49\%), with private clinics, and especially FHOK and MSI, becoming the major source. Within the public sector, hospitals have become a much less important source of contraceptive information and services, reflecting the decentralization of service delivery; indeed, nine out of 10 facilities now provide only pills, condoms and injectables and merely four out of 10 offer four methods. The availability of clinical family planning services has declined concomitantly as skilled clinical providers have either left the field or focused their practice on more lucrative clinical services.

An important trend in the provision and use of family planning services in Kenya over the past 15 years has been the increasing dominance of injectables and the concomitant reduction in the provision of all other methods, especially LAPMs (see Figure 8). As the contraceptive prevalence rate did not increase between 1998 and 2003, most of this increase in injectable use represents either switching from other methods, such as pills, IUDs and condoms, or new users starting with injectables. In either case, given the high discontinuation rates at 12 -months for reasons apart from wanting to become pregnant ( $42 \%$ of pill users and $28 \%$ of injectable users), and weak logistic systems leading to stockouts in public clinics, many potential users with unmet need were left without adequate protection from unwanted pregnancy.

\section{Figure 8: Changes in contraceptive method mix over time}

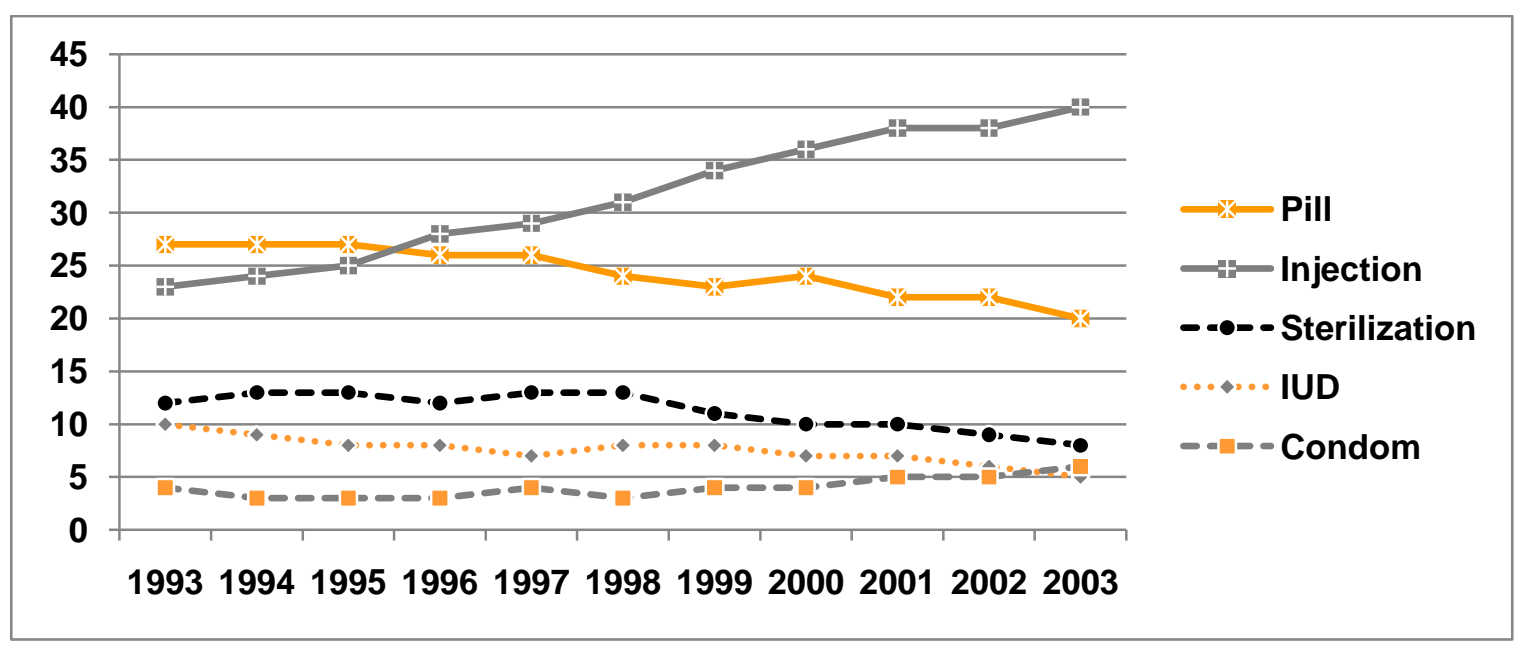

Source: Kenya DHS 2003

\section{Trends in use of family planning}

A sustained increase in the use of family planning until 1998 has clearly been a major factor in the fertility transition, providing women and couples with the means to help them plan pregnancies. From 1998 to 2003, contraceptive use among currently married women did not increase, remaining at 39 percent $^{4}$. This plateauing was also found for contraceptive prevalence among all women at 30 percent.

In understanding trends in family planning use, it is important to look at what has been happening among sub-populations. Importantly, there has been a steadily increasing use of family planning among women who are currently sexually active (defined as having sex in the previous four weeks) as shown in Figure 9. This is particularly pronounced among never married women, with a 22 percentage point increase over the period 1993-2003, from 35 to 57 percent,

$4 \quad$ Figure 2 gives a prevalence rate of $41 \%$ for 2003. This is because women living in the northern areas of Kenya were excluded to allow a comparison with surveys undertaken in previous years. 
largely as the result of increased condom use. Moreover, median age at first sex has increased significantly over the 1998 to 2003 period, from 17.3 to 18.1 years among women aged 20-24 (and from 16.2 to 16.6 among young men). This indicates that younger unmarried adults are not only starting sex later but are also more likely to be using contraception when they are sexually active. This is a highly encouraging trend that needs to be sustained.

Figure 9: Trends in the use of contraception among women who had sex in the past four weeks

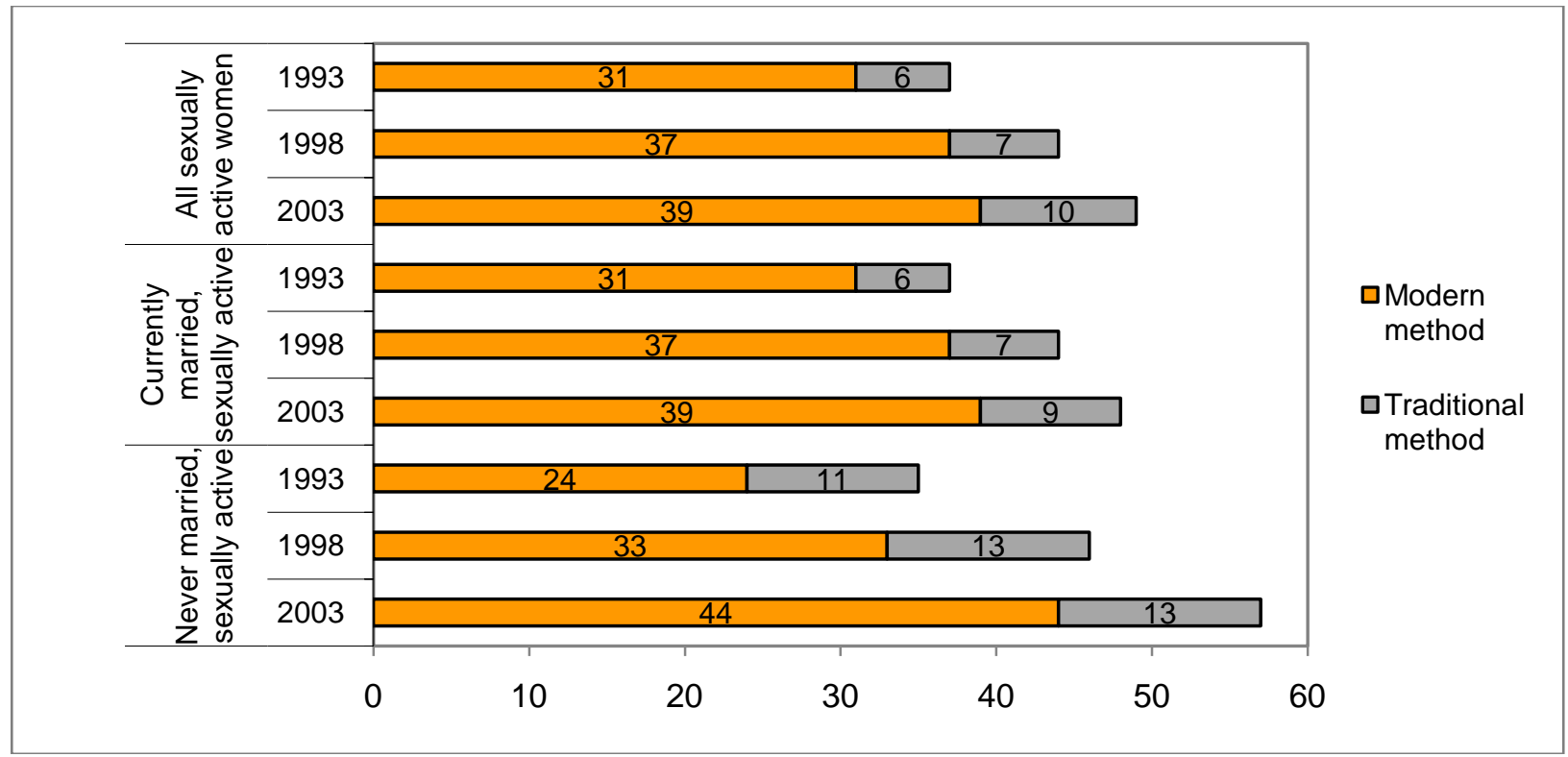

Source: Westoff and Blanc 2006

There are a couple of important implications in these trends. First, the stalled use of family planning among all women and among currently married women is often attributed, at least partially, to the frequent stockouts and other problems in ensuring a continuous supply of contraceptive commodities to the range of service outlets in Kenya, problems that still continue. But these data indicate that sexually active women who want to use contraception appear to be able to do so, although probably with greater effort and certainly at higher cost. The stall in use seen in the population overall probably reflect other reasons for non-use than non-availability (Westoff and Cross 2006).

Secondly, as most never married women are young, their current use of family planning may indicate a normative behaviour that will continue into marriage. As young women enter into longer-standing relationships, however, the use of condoms for pregnancy protection as well as an infection prevention strategy is certainly going to decline.

Another notable trend can be seen in terms of women's educational status. While family planning use stalled from 1998-2003 for currently married women with primary education, for those with no education use decreased from 23 to 16 percent and for those with at least secondary education use increased from 52 to 62 percent.

Rapid urbanization in Kenya has led to an increasing focus of attention on family planning trends among urban dwellers. On a positive note, contraceptive use among currently married urban women (48\%) is much higher than among rural women (37\%). However, this aggregate figure masks tremendous variations within urban dwellers, with use of any method ranging from 60 percent among the highly educated to 14 percent among those with no education; a similar distribution in prevalence is found across wealth quintiles, ranging from 48 to 13 percent. Those 
with no education and the lowest level of wealth are likely to live primarily in the urban slums, highlighting the urgent need for family planning programmes that can reach this highly disadvantaged population.

\section{Need for family planning}

Trends in the effectiveness of the family planning programme in reducing unwanted fertility can also be seen in terms of unmet need. Between 1993 and 1998, total unmet need decreased substantially, from 36 to 24 percent, with similar decreases for both spacing and limiting. Between 1998 and 2003, however, total unmet need actually increased by one percentage point, and this levelling off was fairly uniform across all sub-populations. The only exceptions over this time period were Coast Province with a five percentage point decrease in unmet need (although still high at 25\%), and Nyanza Province with a nine percentage point increase (taking it to 35\%), highlighting the diversity with which the family planning programme is evolving across the country.

Overall, total demand for family planning (i.e. all women with a met or unmet need) was about 66 percent. However, the proportion of women with satisfied demand was much higher among unmarried women $(83 \%)$ than married women $(63 \%)$; indeed, only three percent of unmarried women, compared with 25 percent of married women, had an unmet need for family planning, indicating the need to prioritize increased attention to reaching married women. Unmet need is also higher among women younger than 35 years, living in rural areas, and with the lowest wealth quintiles.

Moreover, although demand for family planning is only 10 percent in North Eastern province, satisfied demand is incredibly low, at 1.6 percent, indicating that this province should be considered a priority for addressing both wanted and unwanted fertility. Conversely, total demand for family planning is 80 percent in Central province and 86 percent of this demand is satisfied, with unmet need at only 11 percent.

As may be expected given the density of service outlets, urban areas $(17 \%)$ have much lower levels of unmet need than rural areas $(27 \%)$ and levels of satisfied demand are much higher $(74 \%$ vs. $60 \%$ ). But as with fertility rates, there are also tremendous disparities between urban subpopulations. Interestingly, the highest levels of unmet need in urban areas $(25 \%)$ are among those who have completed primary education and are in the second and middle wealth quintiles, higher than the poorest and those with no education $(15-20 \%)$, which probably reflects the higher demand for family planning among these groups. This suggests that family planning activities in urban areas need to be differentiated between those targeting the poorest and least educated, for whom demand creation is still required, and those targeting the emerging middle class for who access to services seems to be a bigger priority.

These levels of unmet need and unsatisfied demand inevitably lead to a substantial proportion of unplanned births - 45 percent according to the $2003 \mathrm{KDHS}$, of which 20 percent were unwanted. The proportion of births that were unwanted represents a doubling (from 11\%) over the previous DHS in 1998. This large increase in a short period of time reinforces the difficulties in meeting contraceptive need experienced in this period, especially among older women for who over 45 percent of births are unwanted. 
What proportion of unplanned pregnancies are terminated through induced abortion is extremely difficult to estimate; the largest survey to date ${ }^{5}$ indicates an abortion rate (number of spontaneous and induced abortions) per 1,000 women aged 15-49 years of 46 and an abortion ratio per 100 live births of 29.

\section{What happened and why: Implications for population dynamics and development planning in Kenya}

\section{Summary of relevant developments in population issues in Kenya}

- The total fertility rate declined rapidly from a high of 8.1 in 1977 to 4.7 in 1998, probably due to a strong family planning programme that focused on both providing contraception (to reduce unwanted fertility) and creating a demand for family planning (to reduce wanted fertility). It then increased to 4.8 in 2003 due to a number of reasons outlined below.

- From 1998 to 2003, total fertility increased significantly among those with no education (from 5.8 to 6.7 ) and those in the lowest wealth quintile (from 6.5 to 7.8 ). While there was no change in those in the highest wealth quintile, the fertility decline continued among the most educated, from 4.0 in 1993 to 3.2 in 2003.

- Unwanted fertility declined rapidly to a low of 1.2 in 1998, probably due to an enormous expansion in the availability of a range of contraceptives from a diversity of sources. The decline then stalled and increased slightly to 1.3 births per woman in 2003, probably due to a sustained diminishment in the effectiveness of the public sector delivery systems, including withdrawal of community-based distribution of contraceptive services. This increase in unwanted fertility was highest among the poorest quintile, suggesting that family planning services were becoming less accessible to the poorest of the poor.

- Wanted fertility declined rapidly to a low of 3.4 in 1993, probably because of the tremendous investment in information and education campaigns that promoted a small family norm and birth spacing. It then increased slightly to 3.5 births per woman in 1998 and 2003. This may be due to a gradual reduction in investments in strategies for influencing fertility preferences and family size, such as IEC and CBD programmes.

- A simultaneous decrease in investment in child health services adversely affected their coverage, leading to an increase in child mortality, which may also have influenced familial decisions around childbearing, planning on replacement of children who died or were seen to be at increased risk due to poverty. This increase in wanted fertility occurred in both the poorest of the poor and the least educated (often characteristics of the same population), which were also those most adversely affected by increasing child mortality rates and HIV/AIDS rates. Muslims also showed a sustained and significant decrease in those wanting no more children.

- The fertility stall occurred across all age groups. Moreover, urban teenagers, and especially those living in Nairobi province, had substantial increases in pregnancy rates between 1998 and 2003. Among teenagers with no education, the proportion ever pregnant has steadily increased, reaching over one half by 2003 .

5 Ipas. 2004. A National Assessment of the Magnitude and Complications of Unsafe Abortion in Kenya, Chapel Hill, North Carolina: Ipas. 
- The stall occurred in both rural and urban areas. Despite a previous decline, an increase in fertility of about 0.5 births was observed in Rift Valley and Nyanza provinces over the period 1998 to 2003. Only Central Province has sustained the transition.

- Contraceptive prevalence increased rapidly to a high of 30 percent among all women (39\% among currently married women) in 1998 due to the substantial investments in contraceptive service delivery systems and demand creation campaigns. Prevalence did not increase any further in 2003, which appears to reflect both the stall in declining wanted fertility, and a lack of investment in family planning information and services by the Government, together with decreasing investment by development partners as their focus shifted to addressing the HIV/AIDS pandemic.

- However, contraceptive prevalence continued to increase among all sexually active women; this increase was even more marked among never married sexually active women. Thus women who were sufficiently motivated and had the time and resources to seek services were able to access and use contraceptives, despite increasing weaknesses in the delivery systems and frequent commodity stockouts.

- Contraceptive prevalence decreased significantly among women with no education and with no children, but increased among the more educated. In urban areas, among those most likely to live in slum settlements, i.e. the poorest and least educated, contraceptive prevalence is now below 15 percent.

- Contraceptive prevalence increased in Central, Eastern or Western provinces, but decreased in Nairobi and Nyanza.

- The mix of methods reduced drastically over this period, with injectables replacing the pill and LAPMs for both spacing and limiting births. Overall contraceptive failure and discontinuation rates have not improved.

- Provision of family planning services has shifted increasingly to the private sector, with over half of all users now obtaining their commodities from non-public sources. Within the public sector, primary level facilities are the main source. Both trends suggest that supply methods are the principle contraceptives available and referral systems for clinical services are poorly defined.

- Whether the HIV/AIDS epidemic has influenced the fertility transition is unclear. Certainly it has adversely affected the level of financial and human resources invested in family planning, but whether it influences individuals and couples' fertility decisions is not clear, given available evidence.

- Kenya has long been a regional leader in developing strong population-related policies, as well as norms, standards and guidelines for service delivery. Political and social commitment to implementing these policies has wavered over the years, however, in part due to a well-supported and active opposition to reproductive health, led largely by conservative and influential religious leaders. 


\section{Critical issues}

Participants at the meeting reviewed and discussed these analyses in depth. While definitive solutions to the issue of plateauing fertility did not emerge, the discussion did highlight the interest of the participants and the potential for increase policy dialogue and the need for a renewed focus on evidence for decision making. Some of the most pertinent observations can be summarized as follows:

Fertility and economic development: Has the stall occurred because this fertility level is appropriate for Kenya's current level of economic development? Will a further decline in the fertility rate only occur with greater economic development or can a "second transition" be stimulated through other factors, such as a more dynamic family planning programme?

Fertility, family planning and poverty: The poorest in society have the highest wanted and unwanted fertility rates and are the least able to access information and services, for family planning and maternal, infant and child health. Given that one half of the Kenyan population live below the poverty line, these inequities in the right to access critical health services need to be addressed to reduce their vulnerability as this the sub-population driving the transition stall.

Fertility preferences of the youth: As the future drivers of a possible second fertility transition, understanding the fertility desires and value of children to adolescents and young adults is critical to inform appropriate educational and service activities; this is especially important for the urban youth.

Fertility, family planning and the urban poor: The Kenyan Government's long-term economic development plan, Vision 2030, highlights the vast growth in urban populations anticipated over this period. Little attention is paid in the plan to addressing the fertility, family planning and other reproductive health needs of this population, and especially the urban poor. Advocacy is needed to emphasize that these issues are addressed within the Vision 2030 framework.

Mortality, AIDS and fertility: How important are the associations between child mortality rates and fertility preferences, and what role does death from paediatric AIDS play in influencing fertility decisions among people living with HIV/AIDS?

Political and social support for population issues: Despite excellent policies, there is a fundamental lack of support in the country for pro-actively addressing population issues, both among political, religious and social leaders, as well as a paucity of institutional leadership within government and civil society structures. The limited commitment and leadership that does exist should be strengthened and supported to increase its visibility and effectiveness.

Strengthening family planning services: Family planning information and services have weakened over the past 15 years. Attention needs to be paid both to advocating for greater commitment and allocation of resources (financial and human) and to strengthening provision of information and services. Despite the policy of encouraging linkage of family planning with other reproductive health services (including HIV/AIDS), resources need to be invested in strengthening the availability and quality of a full range of contraceptives, which can be provided both as a stand-alone and integrated service.

Address both unwanted and wanted fertility: Strengthened family planning services need to both reduce unwanted fertility (i.e. meet existing demand) and utilize social communication, including mass media, interpersonal and community-based communication strategies, to reduce wanted fertility (i.e. influence desire for more children), especially among the poorest and least 
educated. Contraceptive commodity security needs urgent attention, as does broadening the method mix and the availability and skills of clinical providers, especially to reduce the unmet need for limiting births.

Greater understanding of client and provider needs through research: Operations research can play a crucial role in testing innovative and modifying existing information and service delivery models to revitalize family planning services. Many of the relationships identified above need further research to fully understand their dynamics and relationship with the fertility transition. As most service delivery networks function within regional, cultural and infrastructure constraints, additional investments should be made to tailor models to local context and resource pools.

\section{Revitalizing the fertility transition}

There was universal agreement at the stakeholders' meeting that the fertility transition has stalled in Kenya and that, for reasons of economic development, health and reproductive rights, there is an urgent need to stimulate a further transition that in the total fertility rate and better enable individuals and couples to achieve their reproductive intentions. Drawing from the analyses and discussions, the following recommendations can be made:

- Undertake policy analyses that examine the association between population size, fertility rates and birth spacing with economic development and maternal, infant and child health. In particular, analyses should focus on the implications of current and future population size and growth for successfully implementing the Vision 2030 plan and on achievement of the Millennium Development Goals. Specify the opportunities for policy change, which might influence the potential for achievement of these goals, and the consequences for public investment of failing to act. Identify the required changes in existing policy documents, operational policies of public sector providers and the determinants of performance in public and private family planning provider networks to identify targets for change. Explore opportunities for pay for performance and alternative financing schemes for improved service delivery and reliable support systems.

- Support the creation and activities of a consortium of government, non-government and civil society institutions, together with well-respected individual 'champions', that can cohesively advocate for greater attention to population growth, family planning and other reproductive health issues by national leaders, regional opinion leaders and influential stakeholders and the general population. Chart public opinion about support for family planning and other reproductive health services and movement of related social norms. Priority issues could include: greater allocation of governmental resources; more active engagement with opponents of reproductive health service provision; innovative involvement of the private sector including public-private partnerships in services delivery; and highlighting the inequities in access to essential reproductive health services for the poor, less educated and those living in remote areas.

- Undertake and broadly disseminate social science research to better understand the social and behavioural determinants of the stalled transition, for example: i) the reasons for increases in wanted fertility among various sub-populations; ii) the influence of perceptions and experience of HIV/AIDS on fertility decisions of infected and affected individuals and couples; iii) the association between child (and infant) mortality on fertility behaviours; iv) the reasons for rapid increases in pregnancy rates among urban teenagers; v) the implications 
of steadily increasing levels of contraceptive use among sexually active women when overall contraceptive prevalence is stagnating; and vi) the role of men in changing social norms around wanted fertility and investments in family planning services and other reproductive health services.

- Support operations research to develop and systematically evaluate a series of innovative interventions that could guide strengthening of family planning information and services to address identified weaknesses. Examples include:

$\checkmark$ Increasing awareness of the benefits of and support for a smaller family norm through mass media and interpersonal communications strategies;

$\checkmark$ Increasing approval of family planning generally and understanding of the relative benefits and drawbacks of a wide range of contraceptive methods, especially the use of long-acting methods for both birth spacing and limiting, and how to address the health concerns of side effects in continuing use of contraceptive methods;

$\checkmark$ Increasing access to and use of family planning by the poorest of the poor and least educated, in both urban and rural settings, through a range of interventions such as increasing the role of the private sector and continued task shifting of service responsibilities to a range of paramedical personnel;

$\checkmark$ Developing innovative financing methods that reduce the cost of family planning use to the poorest clients;

$\checkmark$ Enabling effective implementation of the Government's 'community health strategy';

$\checkmark$ Integrating family planning into maternal and newborn health services;

$\checkmark$ Engaging men and boys through targeted messaging and involvement in selected services delivery.

In conclusion, the review of the available data, policy issues and options and the call for renewed evidence is suggestive of the continued interest, and indeed concern, about the consequences of stalled fertility and poor quality of services for individuals and the development scenarios of Kenya. The focus of this brief, which is being communicated widely in Kenya, is to provide an overview of the most critical issues to stimulate further policy dialogue and seek the resources within Kenya and from the donor community concerned about the development issues affected by stall fertility and more rapid population growth in the coming decades. 


\section{Documents consulted}

Ajayi, A and Kekovole J. 1998. "Kenya's population policy: From apathy to effectiveness," in Anrudh Jain (ed.), Do Population Policies Matter? Fertility and Politics in Egypt, India, Kenya, and Mexico. New York: Population Council.

Biddlecom A. 2008. “Abortion in Kenya”, In Brief No.4, New York: Guttmacher Institute.

Bongaarts J. 2008. "Fertility transitions in the developing world: Progress or stagnation?" Studies in Family Planning, 39(2), 2008, pp. 105-110.

Central Bureau of Statistics (CBS) [Kenya]. 1980. Kenya Fertility Survey 1977-1978. World Fertility Survey Programme, Nairobi, Kenya: Central Bureau of Statistics.

Central Bureau of Statistics (CBS) [Kenya]. 1984. Kenya Contraceptive Prevalence Survey 1984. First Report. Ministry of Planning and National Development. Contraceptive Prevalence Survey Programme.

Central Bureau of Statistics (CBS) [Kenya] Ministry of Health (MOH) [Kenya], and ORC Macro. 2004. Kenya Demographic and Health Survey 2003. Calverton, Maryland: CBS, MOH, and ORC Macro.

Crichton J. 2008. "Changing fortunes: analysis of fluctuating policy space for family planning in Kenya", Health Policy and Planning, 23(5):339-350.

Ipas. 2004. A National Assessment of the Magnitude and Complications of Unsafe Abortion in Kenya, Chapel Hill, North Carolina: Ipas.

Karanja J, Njoroge P and Orero S. 2005. Impact of Trends in Community Based Family Planning On Contraceptive Prevalence Rate, Working Paper No. 8, Nairobi, Kenya: National Coordinating Agency for Population and Development.

Koome P, Nturibi D and Kichamu G. 2005. The Effect of Declining Family Planning IEC Efforts on Contraceptive Behaviour, Working Paper No. 7, Nairobi, Kenya: National Coordinating Agency for Population and Development.

Magadi, M., Zulu E, Ezeh A, and Curtis S. 2001. Contraceptive use dynamics in Kenya: further analysis of Demographic and Health Survey (DHS) data. Nairobi, Kenya and Calverton, Maryland: Africa Population and Health Research Centre (APHRC) and MEASURE Evaluation Project, ORC Macro.

Magadi M and Agwanda A. 2007. The Link between HIV/AIDS and Recent Fertility Patterns in Kenya, Working Paper 07-92, Chapel Hill, North Carolina: Measure Evaluation, University of North Carolina.

Obonyo B, Otieno F and Muga R. 2005. Effect of Infant and Child Mortality on Fertility in Kenya, Working Paper No. 2, Nairobi, Kenya: National Coordinating Agency for Population and Development.

Westoff C and Cross A. 2006. The Stall in the Fertility Transition in Kenya, DHS Analytical Studies No. 9. Calverton, Maryland: ORC Macro. 


\section{Participants at stakeholder meeting}

\begin{tabular}{|l|l|}
\hline Name & Organization \\
\hline Ominde Achola & GTZ/Options Reproductive Health Programme Support \\
\hline Eliwo Akoto & Centre for African Family Studies \\
\hline Ian Askew & Population Council \\
\hline Mary Anne Burris & Trust for Indigenous Culture and Health \\
\hline Alex Ezeh & Africa Population and Health Research Centre \\
\hline Alan Ferguson & Constella Futures \\
\hline Sahlu Haile & David and Lucile Packard Foundation \\
\hline Lawrence Ikamari & Population Studies and Research Institute, University of Nairobi \\
\hline Sam Kalibala & Population Council \\
\hline Musimbi Kanyoro & David and Lucile Packard Foundation \\
\hline Charity Karonya & Planned Parenthood Federation of America - International \\
\hline Dan Kaseje & Tropical Institute of Community Health, Great Lakes University \\
\hline Boniface K'Oyugi & National Coordinating Agency for Population and Development \\
\hline Sheila Macharia & USAID/Kenya \\
\hline Gabriel Masotho & Ipas, South Africa \\
\hline Jane Menken & University of Colorado, APHRC Board Member \\
\hline Muraguri Muchira & Family Health Options of Kenya \\
\hline Richard Muga & Tropical Institute of Community Health, Great Lakes University \\
\hline Francis Munene & Ministry of Justice, National Cohesion \& Constitutional Affairs \\
\hline Veronica Musembi & Population Services International/Kenya \\
\hline Walter Odhiambo & Marie Stopes, Kenya \\
\hline Joyce Ombeva & Population Council \\
\hline Francis Onyango & Population Council \\
\hline Sarah Onyango & Planned Parenthood Federation of America - International \\
\hline Victoria Rumbold & Population Council \\
\hline Salina Sanou & Forum for African Women Educationalists \\
\hline William Stones & Aga Khan University, Nairobi \\
\hline
\end{tabular}


General Accident House Ralph Bunche Road

Nairobi

Kenya

Tel: +254-2713-480

Fax: +254-2713-479
One Dag Hammarskjold Plaza, New York 1 Dag Hammarskjold Plaza 9th Floor

New York NY

USA 10017

Tel: +1 2123390500

Fax: +1 2127556052

\section{(P) Population Council \\ www.popcouncil.org}

